\title{
Self-Esteem Scale of the Vietnam Minors: Cross-Cultural Adaptation of ETES
}

\author{
Trinh Thi Linh ${ }^{*}$, Nguyen Thi Anh Thu1, Nguyen Dieu Huong2 \\ ${ }^{1}$ Faculty of Psychology, University of Social Sciences and Humanities Affiliated to Vietnam National University, \\ Hanoi, Vietnam \\ ${ }^{2}$ Ministry of Science and Technology, Hanoi, Vietnam \\ Email: *anhlinh huong@yahoo.com
}

Received 8 July 2014; revised 5 August 2014; accepted 1 September 2014

Copyright (C) 2014 by authors and Scientific Research Publishing Inc.

This work is licensed under the Creative Commons Attribution International License (CC BY).

http://creativecommons.org/licenses/by/4.0/

c) (i) Open Access

\section{Abstract}

The purpose of this article is to introduce self-esteem scale associated with the culture of Vietnam. In essence, this is the process of cross-cultural adaptation of self-esteem scales that colleagues from the University of Toulouse II-Le Mirail (French Republic) establish for participant groups who are Vietnam minors. Results factor analysis with SPSS and Lisrel software has allowed us to obtain the scale consisting of 21 items, focusing for 4 contents: family self, social self, physical self, and academic self. Comparing with the study that the Vietnamese colleagues have conducted, we found that the research results have confirmed the importance of self of family to participant groups who are Vietnam minors, whereas emotional self and future self do not get results possible. We believe that Vietnam culture, especially Confucianism and Buddhism may explain the result of this research.

\section{Keywords}

Self-Esteem, Self Family, The Vietnam Minors

\section{Introduction}

\section{The Self in Vietnam Culture}

In the traditional family of Vietnam, individual identity is often determined by their role in the group as well as their relationships with others, especially with family members. So the self usually describe the dependency relationships in this society. In other words, in this culture, the identity of each person cannot easily be separated

${ }^{*}$ Corresponding author. 
from the surrounding environment, on the contrary, it is closely connected with the system of social relationships in which each person's own name is not mentioned (Do Long, 2000).

A review of research on the world allows us to assert that self definition changes from culture to other cultures (Mashaba, 1996; Kareem \& Littlewood, 2000; Dang, Tran, \& Lescarret, 2005). Cultures set up the various aspects of self like the way that people perceive each other. Markus and Kitayama (1991) have shown that culture decides the way in which each person who perceives themselves, independently, separates from the other or Vice versa is in close relation with the object. The self usually linked to a specific individual is in the Eastern countries, while in Western countries, the self was set up based on the role of social relationships (Tafarodi et al., 1999).

In Vietnam, the concept of self seems still fresh. According to our understanding, no self-esteem tool measuring themselves is constructed in the framework of a psychological study of Vietnam. We found that the measurement tools currently used in this field mainly derived from the study of French or American, for example, the self-esteem scale of Tououse (Oubrayrie et al., 1994), the self-esteem inventory of Coopersmith (1984), the scale of Rosenberg (1965), Harter (1982)... These tools have been translated into Vietnamese and increasingly widely used in psychological practice. However, the translation of a measurement tool do not necessarily ensure a culturally respectively. The study of Dang (2006) has shown that the self-esteem scale of Toulouse based on the characteristics of the national culture of the West is not entirely corresponding to the Vietnamese participants. The authors also pointed out the necessity to add another important dimension to the people of Vietnam, such as the family self. We have found that adding the family self in the self-esteem scales for Vietnamese male minors is perfectly reasonable and necessary because in any country, the family is the foundation, the first social group that joins the young. Through this, the child's personality is formed gradually. Meanwhile, like many other Eastern countries, Vietnam is a country where people focus on emotion rather than reason. The Vietnamese always attaches importance to family life; they always keep in mind that "Blood is thicker than water" (Một giọt máu đào hơn ao nước lã). In other words, the Vietnamese community has always shown very clearly in real life what is the first in a family practice. Therefore, we believe that if the will is lacking in the field of self-esteem itself, Vietnam minors will not mention the field of family life in their lives.

Before referring to the results of cross-culture adaptive self-esteem scales that we ourselves have done in this study, we think that would be lacking without mention of the difference in language which is related to self-esteem in the context of different cultures.

The concept of self-esteem in Vietnam is still new. In terms of language, it can be said that there is no corresponding term to refer to "self-esteem" in Vietnamese. The great French-Vietnamese dictionary has yet coined the term self-esteem. The English-Vietnamese Dictionary (Le, 2003) have brought out the meaning of the phrase self-esteem, according to which this term is understood as respect for oneself (Dang, 2006).

Recently, the term "tu danh gia ban than" as a result of the translation of the phrase "estime de soi" of French and "self-esteem" of English has been mentioned relatively more. But it should be noted that the term "ca nhan" (Traduction of "individu") is new in Vietnam, which was marked from approximately the last decade of the twentieth century (Marr, 2000).

We remind that the distinction in language is to see that traditional Vietnamese people really do not mention the concept of self-esteem, at least not in the same way that West mentioned to this concept. In other words, the Vietnamese people have the habit of not expressing his own self in relationships with other people. However, that does not mean that Vietnamese people do not appreciate their own value, and does not mean that they do not have the capacity or assessment of their own feelings about their own image.

\section{Method}

\subsection{Cross-Culture Adaptation of ETES and EVES Construction}

To consider the self-esteem of minors, usually two techniques used in the field: Product handwritten or verbal self portrait of an answer very liberal to question "who am I?" questionnaire form and scale in terms of attitude. Since the study of Coopersmith $(1959,1967)$ and Rosenberg (1965) is very much a self-esteem scale has been developed to manipulation of the positive and negative body image. The participants can be led to self describe themselves by answering a series of questions. The ownership of personal property, the dedication and the social behavior and encourage stability in terms of the capacity is only for self-esteem report.

Motivated by this, we have to rely on self-esteem scale of Toulouse itself (henceforth called ETES) for mi- 
nors (Oubrayrie et al., 1994; Sordes-Ader et al., 1998). This is also the main construction scale is based on the study of Coopersmith, Rosenberg.

Based on the theoretical framework of multi-dimension (multidimensial Theorie), ETES has been developed to asses five fields: emotional self, social self, academic self, physical self and future self. Those five fields are mined in relation to the way in which individuals perceive themselves and their self acceptance. The three fields first are 3 fields often mentioned in the self-esteem scale. However, the scale of the features of the self-esteem considering themselves taking control of emotions, feelings - there are a few aspects to be studied even if we can find it in sub-scale "personal self" (for example in the scale of the Coopersmith).

ETES Scale includes 60 items (Likert type) and was divided among five areas that we mentioned above. Each field consists of 12 items, including items 6 positive and 6 negative items mean. Scale gives a total score for self-esteem generally and 5 points for each field component mentioned.

During her studies in 2006, the author Dang Hoang Minh has made the first step to adapt this scale. The author has also used the term EVES instead of ETES to define aspirations to build a separate scale for participants who are Vietnam minors.

The first study has no results that have statistical significance for the field of emotion self. In contrast, the items belonging to the social self is very clearly, but when was restructured in perspective and consider more specialized family self. In other words, according to the results of this first study, the family relationships in Vietnam minors is appreciated in relation to self-esteem in general.

Stemming from this research, we wish to adapt the EVES scale for participants who are Vietnam minors aims to test the existence of the sub-scale family self after the adaptation first. Deployed to work correctly and efficiently, we have reviewed the family self sub-scale, and we also set the item sharper emotional self. Because we believe that emotional control is a very important factor in the minors, especially in the context of a society in which the self is often not encouraged to express.

\subsection{The Process of Building EVES Scale for Participants Who Are Vietnam Minors}

In fact, the results of the Dang Hoang Minh's study (Dang, 2006) showed that self-esteem of Vietnam minors express on 3 domains (family self, physical self, and society-academic self). Two domains is emotional self and future self that has not bring the results statistically significant. This prompted us to review all items which have been set up.

The theoretical model when referring to the self definition of Harter (1982), Lawrence (1988) as well as the work of Marsh (1984) has allowed us to retain the original intention to keep the structure of the scale EVES consists of 5 sub-scales (family, physical, social, academic and emotional) distribute of 60 items. The future self was not identified in this study.

\section{Result}

\subsection{The Affirmation of the Family Self}

The process of verifying and building scale EVES has been made in the investigation on the first participants test can be 292 junior high school pupils in Vietnam, ages 13 to 15, including 149 males (51\%) and 142 females (48.6\%).

The result of an analysis exploratory principal component (PCA) with varimax rotation has allowed us to obtain 21 items had a correlation coefficient of 0.5 or more, spread over 4 factors (family self, social self, academic self and physical self).

These 4 factors accounted for $50.98 \%$ of the variance in the component solution. The Kaiser-Meyer-Olkin (KMO) is 0.83 and the Cronbach's alpha coefficient for the total scale score is 0.83 . For each subscale (component), this coefficient score follow: 0.84 for the family self, 0.77 for the social self, 0.71 for the physical self, 0.51 for the academic self. The values of Cronbach's alpha coefficient showed high reliability (internal consistency reliability) of the scale.

To confirm the structure of the scales obtained above, we conducted a formal investigation on the 351 participants who are Vietnam minors, including 166 men and 185 women accounted for $47.3 \%$ and $52.7 \%$. The analytical results confirmed the reliability of the scale obtained ( $\alpha=0.82$ for the total score). In particular, the fam- 
ily self was confirmed with Cronbach's alpha coefficient was high $(\alpha=0.86)$.

Results of data analysis is completely compatible with the structural analysis results are we done with Lisrel software, under which specific data is shown in Figure 1.

Thus, to confirm the validity and reliability of scales EVES, we have assessed according to the value of Chisquare, Adjusted Goodness of Fit Index (AGFI), Root Mean Square Error of Approximation (RMSEA) and Comparative Fit Index (CFI). AGFI value $>0.9$ showed a complete match of the scale (Joreskog \& Amp; Sorbom, 1984). RMSEA $=0.05$ level adjustment. CFI index $>0.9$ also shows the relevance (adequacy) of the scale. In the results of our study, we found AGFI $=0.96$; RMESA $=0.054$ and CFI $=0.89$. These data allow us to confirm that the structure of EVES is perfectly reasonable, ensuring high reliability and high validity.

This feature of self-esteem Vietnamese revealed by the sensitivity of the fabric EVES emphasize the clinical data from pediatric practitioners and psychologists who accentuated to practice the decisive importance of the family in Vietnam (Nguyễn, 1962; Nguyễn, 1994).

\subsection{The Effect of Gender}

We see that in the form of the participants of the study, male minors tend to evaluate themselves more positively than female minors $(F(1.349)=3.63, P>0.05)$. It is entirely compatible with the findings obtained in Europe (Oubrayrie et al., 1996).

Table 1 allows us to recognize the difference was statistically significant between men and women in the field of the physical self $(\mathrm{F}(1.349)=21.00 ; P<0.01)$. We should note that the physical self of the EVES scale can be understood as the capacity sports (athletic abilities) (physical appearance does not always get the results statistically significant after multiple adaptive scales.

\subsection{The Effect of Age}

The study results indicated significant difference statistically evidence $(\mathrm{F}(1.337)=9.01, P>0.01)$ with age in the field self-esteem of Vietnam minors. This result is entirely consistent with what Rodriguez-Tomé (1997) points out in his study (Table 2).

Analysis of the field self-esteem Vietnam minors under the age allows us to recognize the obvious difference of the family self to this participants $(\mathrm{F}(1.337)=8.25 ; P<0.01)$, knowing that the self-esteem is higher in children with lower age. This again reinforces our ideas about the importance of family dimension for Vietnam minors.

\subsection{The Effect of Origin}

The compare the mean of the dimensions of self by origin of Vietnam minors attracted our attention because there is no significant difference statistically between self-esteem of the pupil in general of the children who came from Ha Noi and from other provinces in Vietnam $(\mathrm{F}(2.348)=0.57 ; P>0.05)$.

On the level of self-esteem, we also recorded similar results, except for self-esteem on the social level. In this field, Ha Noi minors have positive self-esteem than children from other provinces $(\mathrm{F}(2.348)=3.001 ; P=0.05)$.

The results of this study suggest to us the idea that the children came from other provinces (not Ha Noi-capital of Vietnam) seems to have high social sensitivity than children who are Hanoi people. However, this does not affect other areas of the child self-esteem. Besides, we also think about the hypothesis of cultural identity in the self-esteem of the child.

\section{Discussion}

The validation of EVES helps us to confirm the existence of the family self on participants who are Vietnam minors. Stability of what my family through various studies have allowed us to confirm the importance of family in child education, especially in the formation and development self of the subjects. The existence of the family self in the structure of the EVES scale is a testament to the structural differences of ETES scale for subject French minors. Of course, we are aware that this does not mean that the level of the family survive in these objects. We think that it is important to set any level above all other words that refer to this value or other value to the self structure only. Despite the significant changes in the socio-economic in recent years, Vietnam minors 


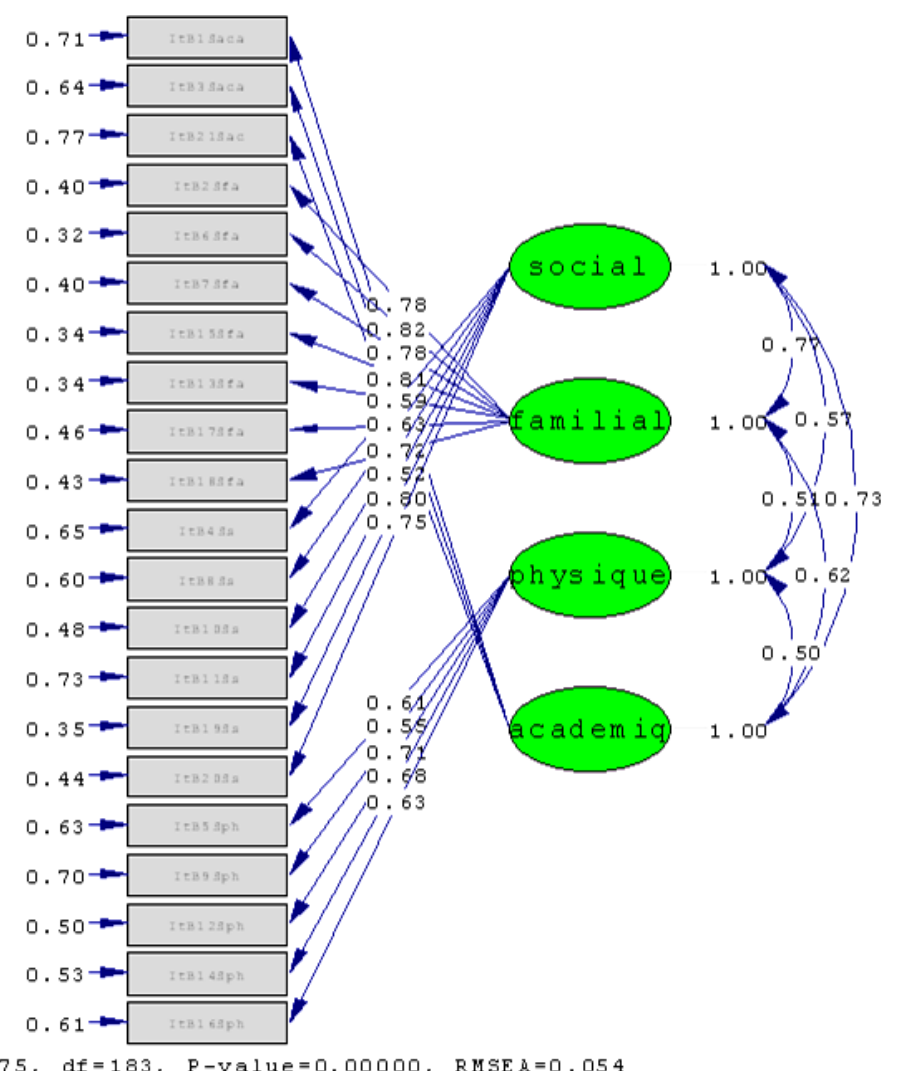

Figure 1. Model of confirmatory structural analysis of the EVES.

Table 1. Compare mean of the dimensions of self by gender.

\begin{tabular}{|c|c|c|c|c|c|c|}
\hline Gender & & General self & Academic self & Family self & Social self & Physique self \\
\hline \multirow[t]{3}{*}{ Boy } & Mean & 77.91 & 9.10 & 28.55 & 22.63 & 17.63 \\
\hline & $\mathrm{N}$ & 166 & 166 & 166 & 166 & 166 \\
\hline & SD & 11.723 & 2.420 & 6.098 & 4.276 & 3.981 \\
\hline \multirow[t]{5}{*}{ Girl } & Mean & 75.45 & 9.52 & 27.95 & 22.44 & 15.55 \\
\hline & $\mathrm{N}$ & 185 & 185 & 185 & 185 & 185 \\
\hline & SD & 12.342 & 2.434 & 6.591 & 4.941 & 4.493 \\
\hline & & 3.631 & 2.651 & 0.786 & 0.145 & 21.007 \\
\hline & & 0.058 & 0.104 & 0.376 & 0.704 & 0.000 \\
\hline
\end{tabular}

Table 2. Compare mean of the dimensions of self age.

\begin{tabular}{|c|c|c|c|c|c|c|}
\hline Age & & General self & Academic self & Family self & Social self & Physique self \\
\hline \multirow[t]{3}{*}{14} & Mean & 78.17 & 9.66 & 28.96 & 22.76 & 16.79 \\
\hline & $\mathrm{N}$ & 213 & 213 & 213 & 213 & 213 \\
\hline & SD & 11.522 & 2.306 & 5.964 & 4.488 & 4.397 \\
\hline \multirow[t]{5}{*}{15} & Mean & 74.10 & 8.87 & 26.91 & 22.25 & 16.07 \\
\hline & $\mathrm{N}$ & 126 & 126 & 126 & 126 & 126 \\
\hline & SD & 12.988 & 2.556 & 6.955 & 4.933 & 4.453 \\
\hline & & 9.015 & 8.714 & 8.251 & 0.966 & 2.087 \\
\hline & & 0.003 & 0.003 & 0.004 & 0.326 & 0.149 \\
\hline
\end{tabular}


still living in a society in which Confucianism and Buddhism are still very present in the social life being of the people. These two thinking are particularly emphasized social relations, especially in family life. So, we can say that Vietnam minors has a symbol of family emerges. That allows them to exist in the family self so much less active depending on the education of their parents.

On the other hand, the adaptive EVES scale is done with many different groups can always confirm the absence of emotional self Vietnam minors, which in the Western world to be recognized very clearly. We think that may explain this if derived from cultural features of Vietnam.

Confucianism and Buddhism are the most important traditions of the Vietnamese culture.

In Confucianism, the concept of self was seen as the center of social relationships (Morris, 1994). Confucianism emphasizes the spiritual development of the self. Therefore, the concept of "tu thân" standard (Cultivate by self) orientation to each of the following qualities (vertue): Nhân (humanitie), Trung (loyal), Hiếu (filial piety), Tiết (loyalty), Nghĩa (Gratitude).

Meanwhile, the Buddhist orientate for each action style "Thú nhất là tu tại gia" (to practice religion, the better it is at home) (Tran, 2000).

Similarly, both Confucianism and Buddhism teach people to be humble. Accordingly, the affirmation of the self or self-seeking in childhood is often seen as narcissistic and so often not encouraged or even suppressed. This allows us to explain why even the Vietnamese have self-esteem of their own value, it is not easy to interpret themselves and with around people. And this has been proven in the physical self aspects such as: Minors in our group be evaluated based on the level of athletic ability rather than rely on the self-image of them.

\section{Conclusion}

In conclusion, from what we have obtained in the study results, we believe that the EVES scale perfectly fit for the participants who are Vietnam minors that work in the field of research, which can be used as a tool to study practical deployment. However, we are also aware that the collection which is not a feasible outcome for future self and emotional self of this group requires that we need to have in-depth studies to further verify this claim.

\section{References}

Coopersmith, S. (1984). Manuel de l'inventaire d'estime de soi. Paris: E.A.P.

Dang, H.-M. (2006). Orientation de soi chez les adolescents vietnamiens souffrant d'une maladie chronique: La dynamique entre l'estime de soi et la représentation de sa propre maladie. Psychology Doctoral Thesis, Toulouse: Université Toulouse II.

Harter, S. (1982). The Perceived Competence Scale for Children. Child Development, 53, 87-97. http://dx.doi.org/10.2307/1129640

Kareem, J., \& Littlewood, R. (2000). Intercultural Therapy. Oxford: Blackwell.

Le, K.-K. (2003). Tù điển Anh-Việt. Hà nội: NXB Thế giới.

Markus, H.-R., \& Kitayama, S. (1991). Culture and the Self: Implications for Cognition, Emotion, and Motivation. Psychological Review, 98, 224-253. http://dx.doi.org/10.1037/0033-295X.98.2.224

Marr, D. G. (2000). Concepts of “Individual” and “Self” in 20th Century Vietnam. Modern Asian Studies, 32, 769-796.

Mashaba, G. (1996). The Nurse: Self and Society, an Introduction to Applied Behavoiral Sciences for Nurse and Health Cares Professionals. Hongkong: Info Medical.

Nguyễn, K. V. (1962). Vietnam, une longue histoire. Hanoi: Ed. du Monde.

Nguyễn, M. D. (1994). Une famille rurale transportée en milieu urbain. Etudes Vietnamiennes, n 3 numéro spécial: Le culte des ancêtres. Problèmes de la famille, Hanoi: Ed. du Monde.

Oubrayrie, N., De Léonardis, M., \& Safont, C. (1994). Un outil pour l'évaluation de l'estime de soi chez l'adolescent: L'etes. Revue Européenne de Psychologie appliquée, 44, 309-317.

Oubrayrie, N., Lescarret O., \& De Léonardis M. (1996). Le contrôle psychologique et l'évaluation de soi de l'enfance à l'adolescence. Enfance, 49, 383-403. http://dx.doi.org/10.3406/enfan.1996.3033

Rodriguez-Tomé, H. (1997). Maturation biologique et changements psychologiques à l'adolescence. In H. Rodriguez-Tomé, S. Jackson, \& F. Bariaud (Eds.), Regards actuels sur l'adolescence (pp. 5-47). Paris: PUF.

Rosenberg, M. (1965). Society and the Adolescent Self-Image. Princeton, NJ: Princeton University Press.

Sordes-Ader, F. et al. (1998). Présentation de l'échelle toulousaine de l’estime de soi: L’etes. In M. Bolognini, \& Y. Prêteur 
T. T. Linh et al.

(Eds.), Estime de soi, perspectives développementales (pp. 167-182). Paris: Delachaux et Niestlé, 310 p.

Tafarodi, R. M., Lang, J. M., \& Smith, A. J. (1999). Self-Esteem and the Cultural Trade-Off: Evidence for the Role of Individualism-Collectivism. Journal of Cross-Cultural Psychology, 30, 620-640.

http://dx.doi.org/10.1177/0022022199030005004

Tran, N. T. (2000). Cơ sở văn hóa Việt Nam. TP Hồ Chí Minh: NXB TP Hồ Chí Minh. 
Scientific Research Publishing (SCIRP) is one of the largest Open Access journal publishers. It is currently publishing more than 200 open access, online, peer-reviewed journals covering a wide range of academic disciplines. SCIRP serves the worldwide academic communities and contributes to the progress and application of science with its publication.

Other selected journals from SCIRP are listed as below. Submit your manuscript to us via either submit@scirp.org or Online Submission Portal.
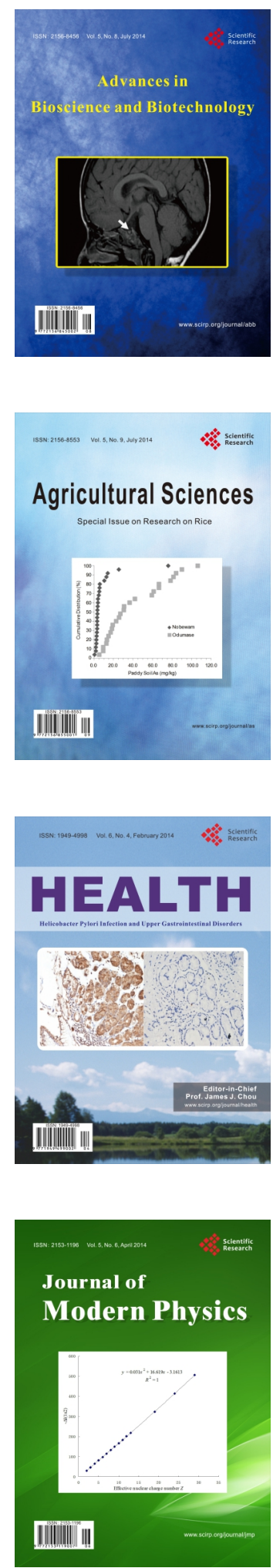
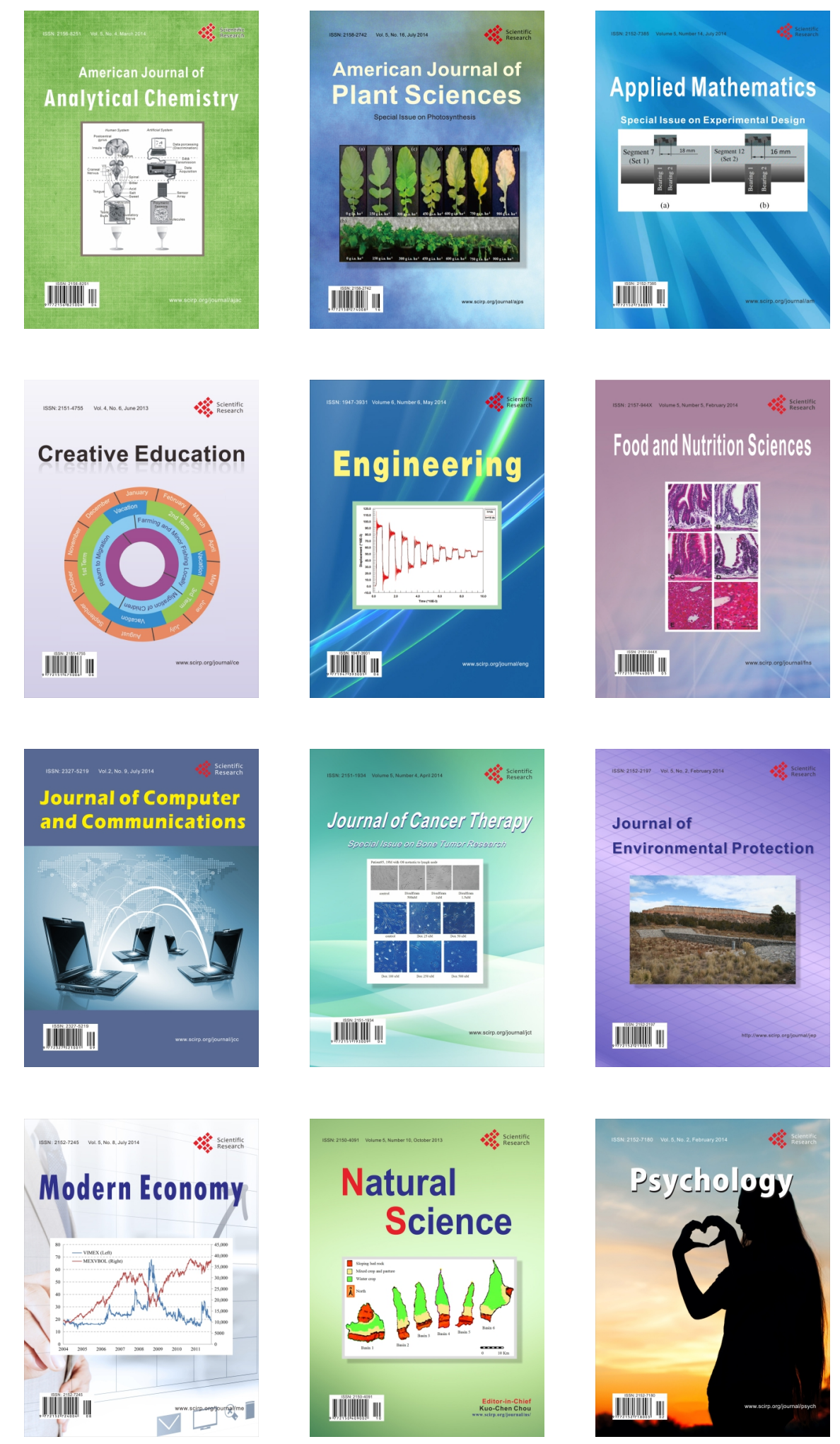